\title{
KAJIAN NILAI LAHAN PERTANIAN DISEKITAR JALAN TOL MANADO-BITUNG (STUDI KASUS DESA TUMALUNTUNG KECAMATAN KAUDITAN KABUPATEN MINAHASA UTARA)
}

\author{
Pinontoan Jennifer Juliana \\ Theodora Maulina Katiandagho \\ Paulus Adrian Pangemanan
}

\begin{tabular}{ll}
\hline Naskah diterima melalui Website Jurnal Ilmiah agrisosioekonomi@unsrat.ac.id & : Kamis, 17 Oktober 2019 \\
Disetujui diterbitkan & : Kamis, 24 Oktober 2019 \\
\hline
\end{tabular}

\begin{abstract}
This research aims to identify (1) the difference in the value of agricultural land before and after becoming the Manado-Bitung toll road and (2) describe the social and economic changes of landowners in tumaluntung village. The study was conducted on the object of the constructions of the Manado-Bitung toll road in the village of Tumaluntung. The time of the study from august to November 2017 and continued in May until June 2019. The method used in this research is descriptive method presented in tabular form. Determination of the sample using the (purposive sampling) method. Primary data used in this study were obtained through interviews with 15 landowners. The secondary data obtained from the Tumaluntung village office, internet through google scholar to get articles from various scientific journals and theses from other tertiary institutions related to the topic of research on the value of agricultural land. The results of the study show that (1) the value of agricultural land before becoming the Manado-Bitung toll road is higher than the value of land after the toll road has been built. (2) improve social status (making current landowners better at meeting needs because land compensation money is used by landowners to be deposited into bank as investment capital such as boarding houses, bakeries, livestock business chiken, showroom, restaurant cars for purchasing capital for cars used for transportation service. ${ }^{* e p r m *}$
\end{abstract}

Keywords: land value, toll road, Manado-Bitung, social economic change

\begin{abstract}
ABSTRAK
Penelitian ini bertujuan mengidentifikasi (1) perbedaan nilai lahan pertanian sebelum dan sesudah menjadi Jalan Tol Manado-Bitung dan (2) mendeskripsikan perubahan sosial dan ekonomi pemilik lahan di Desa Tumaluntung. Penelitian dilakukan pada objek pembangunan Jalan Tol Manado-Bitung di Desa Tumaluntung.Waktu Penelitian berlangsung selama 6 bulan dari bulan Agustus sampai November 2017 dan dilanjutkan pada bulan Mei sampai Juni 2019. Metode yang digunakan dalam penelitian ini adalah metode deskriptif yang disajikan dalam bentuk tabel. Data primer yang digunakan dalam penelitian ini diperoleh melalui wawancara pada 15 pemilik lahan yang dipilih secara sengaja (purposive sampling). Data sekunder diperoleh dari Kantor Desa Tumaluntung dan internet melalui google Cendekia untuk mendapatkan artikel dari berbagai Jurnal Ilmiah dan Skripsi dari perguruan tinggi lain yang berkaitan dengan topik penelitian kajian Nilai Lahan Pertanian sebelum dan sesudah pembangunan jalan. Hasil penelitian menunjukan bahwa (1) nilai lahan pertanian sebelum menjadi jalan Tol Manado-Bitung lebih tinggi dibandingkan dengan nilai lahan setelah Jalan Tol sudah dibangun. (2) meningkatkan status sosial karena menjadikan pemilik lahan saat ini lebih baik dalam pemenuhan kebutuhan dibandingkan sebelumnya. Penggunaan uang ganti rugi lahan oleh pemilik lahan dalam bentuk didepositokan ke Bank, sebagai modal investasi (berupa kos-kosan, toko roti (Bakery), usaha ternak ayam, showroom mobil, restoran), untuk modal berdagang atau untuk modal pembelian mobil yang digunakan untuk jasa transportasi $*{ }^{* e p r m *}$
\end{abstract}

Kata kunci: nilai lahan, jalan tol, Manado-Bitung, perubahan sosial ekonomi 


\section{PENDAHULUAN}

\section{Latar Belakang}

Minahasa Utara merupakan kabupaten yang ada di Provinsi Sulawesi Utara yang dalam pembangunannya mengalami perkembangan yang cukup pesat. Hal ini disebabkan karena kabupaten Minahsa Utara berbatasan langsung dengan kota Manado yang merupakan Ibukota Provinsi Sulawesi Utara sebagai pusat pemerintahan, perekonomian, perdagangan barang dan jasa. Kabupaten Minahasa utara juga berbatasan dengan Kota Bitung yang menjadi kota industri serta Kawasan Khusus Ekonomi (KEK) serta mempunyai alternatif Pelabuhan Internasional (international port) dan merupakan pusat pertumbuhan baru di Asia Pasifik. Pembangunan Jalan Tol Manado-Bitung diharapkan dapat meningkatkan efektifitas dan efisiensi pelayanan jasa distribusi produk kegiatan ekonomi dari pusat pengolahan ke pusat pemasaran. Dalam konteks pembangunan ekonomi, jalan sangat dibutuhkan untuk kelancaran arus faktor produksi maupun pemasaran hasil (Pamungkas, 2009).

Perubahan struktur perekonomian akibat dari berkembangnya suatu wilayah berdampak kepada perubahan nilai ekonomi lahan yang lebih inggi pada kegiatan non pertanian seperti permukiman, perdangangan, industri, dan transportasi dibandingkan pada kegiatan pertanian mengakibatkan meningkatnya perubahan fungsi lahan dari pertanian ke non pertanian (Dardak H. 2005). Hilangnya lahan pertanian akibat pengalihfungsian ke penggunaan non pertanian dapat menimbulkan dampak negatif terhadap berbagai aspek pembangunan. Salah satu dampak negatifnya yaitu tergangunya ketahanan pangan suatu wilayah akibat berkurangnya kapasitas produksi pangan, serta timbulnya permasalahan lingkungan misalnya banjir (Andika,2008). Pembangunan jalan Tol Manado-Bitung yang melintasi daerah Kabupaten Minahasa Utara, telah mengalih fungsikan lahan pertanian menajdi jalan tol. Salah satu desa yang dilintasi jalan Tol ManadoBitung adalah Desa Tumaluntung Kecamatan Kauditan. Pemanfaatan ruang di Desa Tumaluntung terbagi menjadi beberapa kawasan yaitu kawasan pertanian lahan basah, kawasan pertanian lahan kering, kawasan permukiman perdesaan dan kawasan penambakan ikan. Kawasan-kawasan ini telah berubah fungsinya menjadi jalan Tol ManadoBitung.

\section{Rumusan Masalah}

Berdasarkan latar belakang dan kondisi yang terjadi berhubungan dengan alih fungsi lahan dan perbedaan nilai lahan pertanian menjadi lahan non pertanian di atas, maka dapat dirumuskan permasalahan secara berikut:

1. Apakah perubahan fungsi tersebut telah merubah juga nilai lahan di Desa Tumaluntung?

2. Bagaimana perubahan kondisi sosial ekonomi yang dialami oleh para pemilik lahan yang dibebaskan?

\section{Tujuan Penelitian}

Berdasarkan perumusan masalah yang telah disampaikan sebelumnya, maka tujuan dari penelitian ini adalah:

1. Mengidentifikasi perbedaan nilai lahan pertanian sebelum dan sesudah menjadi jalan tol.

2. Mendeskripsikan perubahan sosial dan ekonomi para pemilik lahan yang dialih fungsikan.

\section{Manfaat Penelitian}

Manfaat yang dapat diambil dari penelitian ini adalah sebagai berikut:

1. Dapat memberikan gambaran tentang perubahan nilai lahan dengan adanya perubahan fungsi lahan.

\section{METODE PENELITIAN}

\section{Waktu dan Tempat Penelitian}

Penelitian ini dilaksanakan di Desa Tumaluntung Kecamatan Kauditan Kabupaten Minahasa Utara, penelitian ini akan dilaksanakan selama 4 bulan dari persiapan sampai penyusunan laporan yaitu pada bulan Agustus sampai bulan November 2017.

\section{Jenis Pengumpulan Data}

Data yang digunakan dalam penelitian ini adalah data primer dan data sekunder. Data primer diperoleh langsung dilapangan dengan melakukan wawancara pada pemilik lahan. Data sekunder data yang diperoleh dengan mempelajari dokumen instansi terkait dan kantor pemerintahan Desa Tumaluntung. 


\section{Teknik Pengambilan Sampel}

Penggambilan sampel dilakukan secara purposive sampling. Penelitian ini dilakukan didasarkan pada lokasi dimana lahan pertanian berada, dengan jumlah responden disesuaikan dengan kecukupan data yang digali. Responden dalam penelitian ini berjumlah 15 orang, diantaranya adalah perangkat desa, yang mengetahui persis proses pembebasan lahan guna pembangunan jalan tol, serta para masyarakat yang mengalami sendiri lahan pertanian mereka dibebaskan guna pembangunan jalan tol.

\section{Konsep Pengukuran Variabel}

Variabel-Variabel yang akan diukur dalam penelitian ini adalah:

\section{Identitas Responden}
a. Nama
b. Umur: usia jumlah tahun pemilik lahan dilahirkan sampai saat menjadi objek dalam penelitian (tahun)
c. Jenis Kelamin
d. Tingkat Pendidikan
e. Pekerjaan
f. Pendapatan per bulan
g. Jumlah tanggungan

2. Data Lahan
a. Luas lahan yang dimiliki
b. Luas lahan yang dibebaskan untuk pembangunan jalan tol
c. Harga lahan per $m 2$ ketika dijual untuk pembangunan jalan tol
d. Harga lahan sekarang

3. Alasan menjual lahan

4. Apakah ada penyesalan ketika menjual lahan

5. Investasi yang dilakukan ketika menjual lahan

\section{Metode Analisis Data}

Penelitian ini dilakukan dengan wawancara mengunakan kuisioner kepada pemilik lahan. Dalam penelitian ini terdapat gambaran berbentuk tabel yang bersifat deskriptif.

\section{HASIL DAN PEMBAHASAN}

\section{Kondisi Fisik Wilayah}

Desa Tumaluntung adalah desa tua yang berada di Kecamatan Kauditan Kabupaten Minahasa Utara yang peradabannya telah dimulai sejak zaman purbakala. Luas wilayah Desa Tumaluntung 2400 ha, memanjang $11,5 \mathrm{~km}$ dari kaki Gunung Klabat ke selatan hingga perbatasan dengan Kecamatan Tondano Kabupaten Minahasa. Dari Timur berbatasan dengan Desa Paslaten Kecamatan Kauditan 1,8 km sampai ke barat berbatasan dengan Kecamatan Airmadidi Kabupaten Minahasa Utara.

\section{Kondisi Kependudukan}

Jumlah penduduk Desa Tumaluntung sampai dengan bulan Juni 2017 (Sensus Daerah) tercatat sebanyak 1.106 Kepala Keluarga dengan jumlah penduduk sebanyak 3.681 jiwa yang terdiri atas laki-laki sebanyak 1.860 jiwa dan perempuan sebanyak 1.821 jiwa.

\section{Sarana Pendidikan}

Sarana pendidikan yang terdapat di Desa Tumaluntung sebanyak 2 gedung Taman Kanak-Kanak (TK) Swasta, 2 gedung Sekolah Dasar (SD) Negeri, 1 gedung Sekolah Lanjutan Pertama (SLTP) Swasta, 1 gedung Universitas Swasta. (Laporan Tahunan Desa Tumaluntung 2017).

\section{Karakteristik Responden Umur Responden}

Tabel 1 menunjukkan dimana jumlah responden berusia 10-20 tahun dan 40-50 tahun masing-masing berjumlah 2 orang, responden berusia 30-40 tahun dan 60-70 tahun masing-masing berjumlah 3 orang, responden berusia 50-60 tahun berjumlah 4 orang dan responden berusia 70-80 tahun berjumlah 1 orang. 
Tabel. Jumlah Responden Menurut Umur

\begin{tabular}{lccc}
\hline No & Umur (Tahun) & $\begin{array}{c}\text { Jumlah Responden } \\
\text { (Orang) }\end{array}$ & Persentase (\%) \\
\hline 1 & $10-20$ & 2 & 13.30 \\
2 & $30-40$ & 3 & 20.00 \\
3 & $40-50$ & 2 & 13.30 \\
4 & $50-60$ & 4 & 26.70 \\
5 & $60-70$ & 3 & 20.00 \\
6 & $70-80$ & 1 & 6.70 \\
\hline & Jumlah & 15 & $100 \%$ \\
\hline
\end{tabular}

\section{Tingkat Pendidikan}

Tabel 2 menunjukkan tingkat pendidikan responden terbanyak yaitu tamatan SLTA dengan persentase 66,60 persen, kemudian tamatan S1 dengan persentase 26,70 persen dan tamatan SD dengan persentase 6,60 persen.

\begin{tabular}{lccc}
\multicolumn{4}{c}{ Tabel 2. Jumlah Responden Menurut Tingkat Pendidikan } \\
\hline No & $\begin{array}{c}\text { Tingkat } \\
\text { Pendidikan }\end{array}$ & $\begin{array}{c}\text { Jumlah Responden } \\
\text { (Orang) }\end{array}$ & Persentase (\%) \\
\hline 1 & SD & 1 & 6.70 \\
2 & SMP & - & 0 \\
3 & SLTA & 10 & 66.60 \\
4 & S1 & 4 & 26.70 \\
\hline & Jumlah & 15 & $100 \%$
\end{tabular}

\section{Jenis Pekerjaan}

Tabel 3 menunjukkan bahwa responden yang menekuni pekerjaan sebagai wiraswasta adalah yang terbanyak dengan persentase 46,70 persen. Jumlah responden yang memiliki pekerjaan IRT, Mahasiswa, Petani memiliki jumlah persentase yang sama yaitu masing-masing 13,30 persen dan responden yang memiliki pekerjaan sebagai Honorer dan Pensiunan memiliki Jumlah persentase paling sedikit yaitu masingmasing 6,70 persen.

\begin{tabular}{cccc} 
Tabel 3. Jenis Pekerjaan & & \\
\hline No & $\begin{array}{c}\text { Jenis } \\
\text { Pekerjaan }\end{array}$ & $\begin{array}{c}\text { Jumlah Responden } \\
\text { (orang) }\end{array}$ & Persentase (\%) \\
\hline 1 & IRT & 2 & 13.30 \\
2 & Wiraswasta & 7 & 46.70 \\
3 & Honorer & 1 & 6.70 \\
4 & Pensiunan & 1 & 6.70 \\
5 & Mahasiswa & 2 & 13.30 \\
6 & Petani & 2 & 13.30 \\
\hline & Jumlah & 15 & $100 \%$
\end{tabular}

\section{Jumlah Pendapatan}

Tabel 4 menunjukkan bahwa responden yang memilki jumlah pendapatan 500.000-1.000.000 dan 2.500.000-3.000.000 memiliki jumlah persentase terbanyak yaitu masing-masing 20,00 persen. Responden yang memilki jumlah pendapatan 400.000, 3.000.000-3.500.000, dan 4.500.000-5.000.000 memiliki jumlah persentase yang sama yaitu masingmasing 13,30 persen dan responden yang memiliki jumlah pendapatan paling sedikit dengan persentase 6,70 persen yaitu mereka yang mempunyai jumlah pendapatan 1.000.000-1.500.000, 1.500.000-2.000.000 dan 3.500.000-4.000.000.

\begin{tabular}{lccc} 
Tabel 4. Jumlah Pendapatan & & \\
\hline No & $\begin{array}{c}\text { Jumlah } \\
\text { Pendapatan/Bulan } \\
(\mathbf{R p})\end{array}$ & $\begin{array}{c}\text { Jumlah Responden } \\
(\text { Orang) }\end{array}$ & $\begin{array}{c}\text { Persentase } \\
(\%)\end{array}$ \\
\hline 1 & $<400.000$ & 2 & 13.30 \\
2 & $500.000-1.000 .000$ & 3 & 20.00 \\
3 & $1.000 .000-1.500 .000$ & 1 & 6.70 \\
4 & $1.500 .000-2.000 .000$ & 1 & 6.70 \\
5 & $2.500 .000-3.000 .000$ & 3 & 20.00 \\
6 & $3.000 .000-3.500 .000$ & 2 & 13.30 \\
7 & $3.500 .000-4.000 .000$ & 1 & 6.70 \\
8 & $4.500 .000-5.000 .000$ & 2 & 13.30 \\
\hline & Jumlah & 15 & $100 \%$ \\
\hline
\end{tabular}

\section{Luas Lahan}

Tabel 5 menunjukkan bahwa luas lahan yang dimiliki pemilik lahan sebelum dibebaskan menjadi jalan tol adalah pemilik lahan yang memilki lahan sempit dengan jumlah persentase 40 persen atau 6 responden, yang mempunyai lahan sedang memiliki jumlah persentase yang sama yaitu masing-masing 13,34 persen dan persentase terendah adalah pemilik lahan yang memilki luas lahan yang luas dengan jumlah persentase 6,70 persen atau 1 orang dari 15 orang responden.

\begin{tabular}{cccc} 
Tabel 5. Luas Lahan Sebelum pembebasan & \\
\hline No & $\begin{array}{c}\text { Luas Lahan } \\
\left(\mathbf{m}^{\mathbf{2}}\right)\end{array}$ & $\begin{array}{c}\text { Jumlah Responden } \\
\text { (Orang) }\end{array}$ & $\begin{array}{c}\text { Persentase } \\
(\%)\end{array}$ \\
\hline 1 & $100-500$ & 6 & 40.00 \\
2 & $500-1.000$ & 2 & 13.30 \\
3 & $1.000-5.000$ & 2 & 13.30 \\
4 & $5.000-10.000$ & 2 & 13.30 \\
5 & $10.000-15.000$ & 2 & 13.30 \\
6 & $20.000-30.000$ & 1 & 6.70 \\
\hline & Jumlah & 15 & $100 \%$ \\
\hline
\end{tabular}


Dalam tabel 6 menunjukkan bahwa pemilik lahan yang memiliki lahan sedang mempunyai jumlah persentase terendah yaitu 13,30 persen atau masing-masing berjumlah 2 orang responden, sedangkan yang memiliki luas lahan yang sempit memiliki jumlah persentase masing-masing 40 persen dan 20 persen.

\begin{tabular}{lcll}
\multicolumn{4}{l}{ Tabel 6. Luas Lahan Yang Dibebaskan } \\
\hline No & $\begin{array}{c}\text { Luas Lahan } \\
\left(\mathbf{m}^{\mathbf{2}}\right)\end{array}$ & $\begin{array}{c}\text { Jumlah Responden } \\
(\text { Orang) }\end{array}$ & $\begin{array}{c}\text { Persentase } \\
(\%)\end{array}$ \\
\hline 1 & $<100-500$ & 6 & 40.00 \\
2 & $500-1.000$ & 3 & 20.00 \\
3 & $1.000-5.000$ & 2 & 13.30 \\
4 & $5.000-10.000$ & 2 & 13.30 \\
5 & $>15.000$ & 2 & 13.30 \\
\hline & Jumlah & 15 & $100 \%$ \\
\hline
\end{tabular}

\section{Nilai Lahan Yang Dibayar Pemerintah Untuk Pembangunan Jalan Tol Manado-Bitung}

Nilai lahan tertinggi dalam hasil penelitian dilapangan Rp.600.000 pada tabel menunjukkan bahwa nilai lahan tertinggi menjadi jumlah persentase terendah yaitu 6,70 persen dengan jumlah responden 1 orang. Sedangkan nilai lahan terendah dalam hasil penelitian dilapangan Rp.115.000 disebabkan karena keberadaan lahan berada jauh dari badan jalan yang dilalui jalan tol menjadi persentase terbanyak dengan jumlah persentase 53,30 persen dengan jumlah responden 8 orang.

Tabel 7. Nilai Lahan Ketika Dijual

\begin{tabular}{cccc}
\hline No & $\begin{array}{c}\text { Nilai Lahan } \\
(\mathbf{R p}),\left(\text { per } \mathbf{~ m}^{2}\right)\end{array}$ & $\begin{array}{c}\text { Jumlah } \\
\text { Responden } \\
\text { (Orang) }\end{array}$ & Persentase (\%) \\
\hline 1 & $<200.000$ & 8 & 53,30 \\
2 & $200.000-500.000$ & 6 & 40,00 \\
3 & $>500.000$ & 1 & 6,70 \\
\hline & Jumlah & 15 & 100
\end{tabular}

Nilai lahan sekarang ketika pembangunan jalan tol dilaksanakan dalam hasil penelitian dilapangan yaitu Rp.100.000 dengan nilai terendah dan menjadi jumlah persentase tertinggi yaitu 80,00 persen dengan jumlah responden 12 orang. Nilai lahan tertinggi setelah pembangunan jalan tol Manado-Bitung dibangun yaitu Rp.500.000 dengan persentase 13,30 persen, persentase terendah yaitu lahan dengan nilai Rp.500.000 dengan jumlah responden 1 orang. Pada tabel 8 memperlihatkan nilai lahan sekarang.

\begin{tabular}{lccc}
\multicolumn{4}{l}{ Tabel 8. Nilai Lahan Sekarang } \\
\hline No & $\begin{array}{c}\text { Nilai Lahan } \\
(\mathbf{R p}),\left(\mathbf{p e r} \mathbf{~ m}^{2}\right)\end{array}$ & $\begin{array}{c}\text { Jumlah Responden } \\
\text { (Orang) }\end{array}$ & $\begin{array}{c}\text { Persentase } \\
(\%)\end{array}$ \\
\hline 1 & $<100.000$ & 12 & 80,00 \\
2 & 500.000 & 2 & 13,30 \\
3 & $>500.000$ & 1 & 6,70 \\
\hline & Jumlah & 15 & 100 \\
\hline
\end{tabular}

\section{Proses Pembebasan Lahan dan Pemberian Uang Ganti Rugi}

Proses pemberian uang ganti rugi lahan dilaksanakan setelah pembebasan lahan dilakukan dengan metode menggunakan tahap pertama dan tahap kedua menyesuaikan nomor bidang yang telah disusun oleh panitia. Pemberian uang ganti rugi tahap pertama berakir pada bulan juni 2019, dan tahap kedua dimulai pada bulan juli 2019 sampai selesai direalisasikan dengan waktu yang telah ditentukan oleh panitia pelaksana.

\section{Faktor-Faktor Yang Muncul Akibat Pembangunan Jalan Tol \\ Faktor Ekonomi}

Dampak ekonomi pembangunan jalan tol di Desa Tumaluntung dapat menciptakan lapangan pekerjaan dan menambah laju pertumbuhan ekonomi didaerah tersebut karena uang ganti rugi lahan dijadikan pemilik lahan untuk berdagang, membuka tempat usaha yang berdampak pada peningkatan pendapatan mereka.

\section{Faktor Sosial}

Pembangunan jalan tol di Desa Tumaluntung mengakibatkan kesenjangan yaitu perubahan hubungan kekeluargaan yang disebabkan karena memperebutkan lahan sebagai hak warisan, hubungan suami-istri menjadi tidak harmonis karena memperebutkan uang ganti rugi lahan. Perubahan hubungan sosial ini sangat penting perannya, hubungan sosial yang baik akan menciptakan rasa aman, rasa aman akan didapatkan sesorang bila hubungan sosialnya memuaskan. 


\section{Faktor-Faktor Pendorong Pemilik Lahan Melepaskan Kepemilikan Lahan}

Hak kepemilikan tanah yang sebagaimana digunakan sebagai lahan pertanian milik masyarakat Desa Tumaluntung memang tidak diperjual belikan karena menjadi hak warisan yang akan diberikan kepada anak-anak untuk dikelolah dan dijadikan sebagai sarana pemenuhan kebutuhan dimasa akan datang. Tapi tidak bisa dipungkiri keberhasilan pemerintah dalam melakukan upaya pembebasan lahan disebabkan musyawarah antara pemilik lahan dan pemerintah untuk mengetahui jenis ganti rugi dan besarnya harga atas kepemilikan tanah oleh pemilik lahan.

\section{Pemanfaatan Uang Ganti Rugi Serta Alih Usaha Yang Dilakukan Pemilik Lahan}

Pemberian uang ganti rugi lahan dimanfaatkan pemilik lahan untuk keperluan sebagai berikut: Pertama, pemilik lahan yang mempunyai lahan luas menerima uang hasil pembebasan lahan dengan jumlah yang sangat besar, dikarenakan pengerjaan pembangunan jalan tol Manado-Bitung menerjang keseluruhan lahan. Oleh karena jumlah uang ganti rugi pembebasan lahan sangat besar pemilik lahan memilih untuk mendepositkan ke bank. Kedua, setelah mendapat uang ganti rugi, pemilik lahan yang umumnya memilki lahan yang sedang dan luas membeli tanah di luar desa, luar kecamatan, bahkan luar kabupaten. Dengan membeli lahan di luar desa mereka bisa memilki lahan lagi, jeda waktu antara proses penerimaan uang ganti rugi tahap pertama dan tahap kedua pemilik lahan yang memilki profesi sebagai petani dapat menggarap lahan baru milik mereka lagi. Ketiga, pemilik lahan yang sebagian lahan pertaniannya terkena pembebasan lahan dalam artinya hanya beberapa dari luas lahanya yang terkena proyek pembangunan jalan tol, sehingga sebagian lahan pertaniannya masih bisa digunakan untuk bertani. Oleh karena itu pemberian uang ganti rugi sangat bermanfaat untuk memenuhi kebutuhan hidup para Keluarga petani untuk beberapa tahun kedepan. Keempat, pemilik lahan dengan lahan kecil memanfaatkan pemberian uang ganti rugi untuk penanaman modal, alokasi penanaman modal digunakan sebagai modal investasi (seperti kost-kosan, toko bakeri, usaha ternak ayam, showroom, restoran) untuk modal berdagang atau untuk modal pembelian sarana transportasi yang digunakan untuk jasa transportasi. Kelima, pemilik lahan yang memilki lahan yang luas ketika lahan pertaniannya terkena pembebasan lahan dalan proyek pembangunan jalan tol, sudah dapat dipastikan bahwa mereka akan menerima uang ganti rugi yang besar. Hal ini membuat pemilik lahan memilih untuk membagikan uang tersebut kepada anak-anak untuk dipakai dalam kelangsungan hidup untuk masa depan mereka dimasa yang akan datang.

\section{KESIMPULAN DAN SARAN}

\section{Kesimpulan}

Berdasarkan hasil penelitian dan pembahasan, dapat disimpulkan bahwa perbedaan nilai lahan pertanian sebelum menjadi jalan Tol Manado-Bitung lebih tinggi dibandingkan nilai lahan sekarang. Pembangunan jalan Tol ManadoBitung merubah status sosial (menjadikan pemilik lahan saat ini lebih baik dalam pemenuhan kebutuhan seperti primer, kebutuhan sekunder, dan kebutuhan tersier). Dapat disimpulkan bahwa pembangunan jalan tol dapat memberikan manfaat dan keuntungan secara ekonomi bagi pemilik lahan.

\section{Saran}

Berdasarkan kesimpulan penelitian, maka penulis merekomendasikan yaitu lahan menambah kenaikan nilai disesuaikan dengan penggunaan lahan tersebut tanpa melihat jarak lahan ke tempat pembangunan yang dilakukan, sehingga faktor sosial ekonomi lebih terarah pada peningkatan kesejahtraan masyarakat.

\section{DAFTAR PUSTAKA}

Andika, 2008. Analisis Nilai Ekonomi Lahan (Land Rent) Pada Lahan Pertanian Dan Permukiman Di Kecamatan Ciampea,Kabupaten Bogor. Skripsi Program Studi Ekonomi Pertanian Dan Sumberdaya Fakultas Pertanian Institut Pertanian Bogor

Dardak Hermanto, 2005. Upaya Pemerintah Memenuhi Kebutuhan Infrastruktur Jalan, Makalah Sarasehan Prospek Pembangunan Jalan Tol di Indonesia. Jakarta.

Pamungkas, Bagus Teguh. 2009. Pengaruh Infrastruktur Ekonomi, Sosial dan Administrasi/Institusi terhadap Pertumbuhan Propinsipropinsi di Indonesia. Skripsi Departemen Ilmu Ekonomi Fakultas Ekonomi Universitas Indonesia. 